zone programme was held during November 7-10 in Montpellier with the help and support of the university there. Speakers from fifteen countries contributed papers under the following sections. (A) Structural and physiological features of the vegetation. This section included papers on ecological classification, the fodder value of desert plants in South Africa, and the effects of land management on arid zone vegetation. (B) Climatic, ecoclimatic and hydrological effects on vegetation. The papers in this section dealt not only with effects of rain and other climatic factors but also with dew measurement and with forests in arid areas. (C) Soil and vegetation. This section covered the effects of soil type, the influence of minor elements and soil microbiology. (D) Influence of other factors. These included overgrazing and soil insects, and a valuable account was given of methods used in Australia in land-use surveys. The symposium as a whole included a number of valuable papers. and provoked keen discussion. Its proceedings will be published.

\section{NEW CHEMICAL LABORATORIES OF THE UNIVERSITY OF SHEFFIELD}

$\mathrm{T}$

HE new chemical laboratories of the University of Sheffield were opened on February 5 by the Earl of Scarbrough, and afterwards honorary degrees were conferred upon Sir Cyril N. Hinshelwood, Prof. C. K. Ingold and Mr. T. A. MeKenna. A single structure now takes the place of laboratories that were formerly separated from one another and from the central stores by a hundred yards horizontally and as many feet vertically in a building without lifts. While the greater part of the cost has been met by grants to the University for that purpose by the University Grants Committee, the Staveley Coal and Iron and the Staveley Iron and Chemical Companies, in response to the appeal for a University Development Fund in 1947, covenanted to contribute a sum of $£ 50,000$ primarily for the benefit of the Chemistry Department. In permanent record of the University's appreciation, the research laboratories in the new Department have been named the Staveley Laboratories.

As the first stage of a larger structure which will be necessary for any significant increase in the present number of students, it consists of a main block facing Brook Hill, with a wing at its eastern end receding obliquely from the street. Provision has been made for additions when necessary at both ends of the block. The four-story building is of steel-framed brick faced with Portland stone; the sloping site allows unrestricted natural lighting to the lowest floor of the wing. The wing consists essentially of four large teaching laboratories, one above the other. From the lowest floor upwards, they are for intermediate classes, advanced inorganic chemistry, physical chemistry and elementary organic chemistry, respectively; each is served by a substore connected to the main store by a goods lift. These teaching laboratories have small rooms attached for special purposes, and in addition there are eight research laboratories and seven small rooms for lecturers.

The various floors are united by staircases at each end of the main block and an emergency staircase at the far end of the wing. There is a passenger lift at the junction of the main block and the wing, and provision has been made for another lift at the west end. The junction of the wing and main block, with

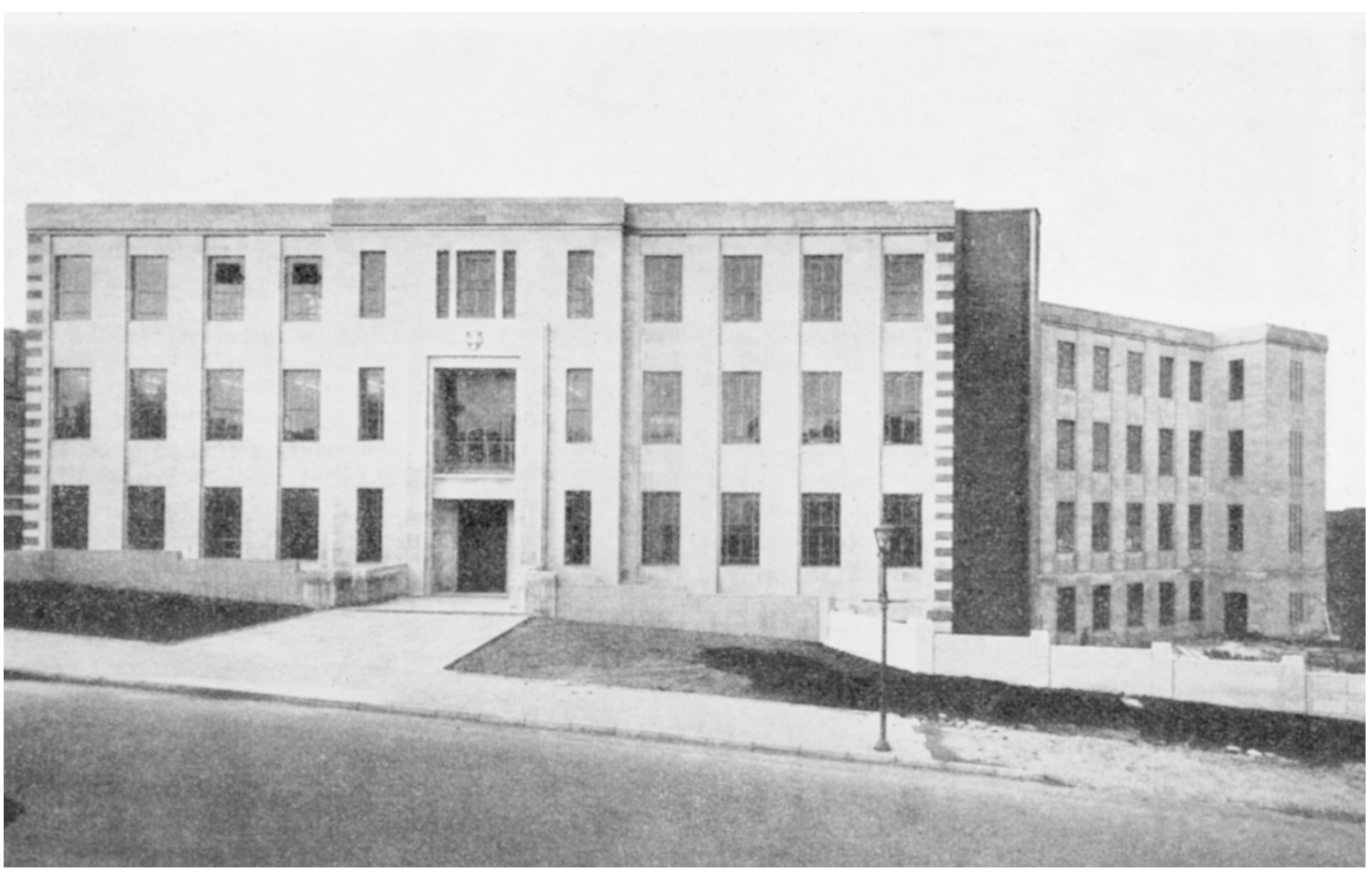

New Chemical Laboratories of the University of Sheffield 
its lifts and staircase, thus constitutes the main distributory channel for the whole building.

On the lower ground floor of the main block are the central stores, with goods entrance and unpacking area, and separate accommodation for dangerous or excisable materials; here also are the mechanics' workshop, glass-blowers' room, analytical preparation room and micro-analytical laboratory, a laboratory for heavier equipment, and the electrical sub-station and calorifiers serving the building. A basement provides further storage facilities, a constanttemperature room, refrigeration room, and rooms for special equipment.

The main entrance is to the ground floor, which has common-rooms for teaching and laboratory staff and for research students, cloak-rooms, X-ray and spectroscopic laboratories, and the main lecture theatre, which seats 250 . This theatre, more than large enough for present departmental needs, is intended to be used also for general university purposes. At the very fully equipped lecture bench are controls governing the window blinds (in sections), the room lighting (in sections), blackboard movement and lighting, and spotlighting of the bench itself. The projection box, in communication with the bench, has $35-\mathrm{mm}$. and $16-\mathrm{mm}$. projectors, microfilm projector, lantern and epidiascope.

The Wynne Library, built out from the western end of the ground floor, has been equipped with steel shelving calculated to cope with the menacing expansion of chemical literature for some ten years. It is named in commemoration of the great services to the University of the third professor of chemistry, the late William Palmer Wynne.

Whereas in the completed building the first floor will be entirely devoted to physical chemistry, three of the seven research laboratories in the main block are at present used for organic chemical research. There are also on this floor a reader's room, dark rooms and other small rooms for special purposes, and a lecture theatre with seating for 120. On the second floor of the main block are the professor's room, a reader's room, lecturer's room, four research laboratories, small rooms for special work, a teaching laboratory for advanced organic chemistry, and a small lecture theatre seating 60 . Rooms for solvent recovery and for conducting dangerous operations are provided on the extensive flat roof.

As a whole, the building provides working places for some 240 undergraduates at any one time, and, including the teaching staff, for 50-60 research workers. Accommodation for the more elementary classes is multiplied by duplication or triplication of lockers, so that places can be found for as many as 450 undergraduates.

The services in the laboratories include high- and low-pressure cold water, hot water, gas, electricity, steam and compressed air, all carried in readily accessible channels $10 \mathrm{ft}$. apart, running vertically and horizontally. In addition to the ordinary a.c. supply at $240 \mathrm{~V}$., three-phase current is available at certain points, and d.c. supply is from mobile rectifiers and batteries. Lighting is in general by tungsten lamps in corridors and lecture theatres, but by fluorescent strip, sometimes of 'colour-matching' type, in teaching and research laboratories. Ventilation is by window and by extractor fans-one for each fume cupboard-which work from the roof. The building is heated by hot water provided from the main University station across Winter Street, operating through panels in the walls.

\section{AN ATLAS OF END-GRAIN PHOTOMICROGRAPHS FOR THE IDENTIFICATION OF HARDWOODS}

A $S$ the number of hardwood timbers from tropical A countries now being placed on the market increases, their identification has become increasingly difficult. The Forest Products Research Laboratory, Princes Risborough, has already produced Bulletin No. 25, "Identification of Hardwoods : A Lens Key", which provides a practical method of timber identification for those lacking laboratory facilities--in other words, for the man out in the forest or in the timber yard. It may not be generally known that, among tropical timbers at least, there may be a close resemblance between a timber of considerable value for structural and other purposes, for example, and another, or more than one, which is of an inferior quality. The fact that the latter exists in greater abundance in the forests and therefore is of easier and cheaper extraction can lead to substitutions which are far from desirable.

The "Lens Key" was prepared for the use of the practical man engaged in the extraction and mar. keting of these more or less new tropical timbers. To indicate its value to the forest man, an illustration may be given. Whenever possible, water transit is the cheapest and easiest for the transport of heavy timber materials. The felled trees after topping are made up into great rafts and floated down the river until they reach the port or checking station. One or more of the rafts may purport to be of the valuable species of timber of the region. Yet it is simple to include a number of logs of the inferior species, the whole raft being passed for payment on the higher royalty scale. Armed with the "Lens Key", the checking officer is in a position to stop this kind of thing.

The Forest Products Research Laboratory has now produced an addition to the "Lens Key" which can be used in conjunction with it. Bulletin No. 26, entitled "An Atlas of End-Grain Photomicrographs for the Identification of Hardwoods"*, supplements the "Lens Key" by providing photomicrographs of the timbers dealt with in the latter and enables users to verify their identifications by comparison with photographs of authentic species. As the author says : "it provides a ready means of checking that a timber is what it is reputed to be". Of course, it is to be understood that the user of the "Atlas" must be able to prepare a cleanly cut end-grain surface of the timber in question. A safety-razor blade can be used for the purpose, as it gives $\mathbf{a}$ sharper and cleaner cut than a knife.

There are 396 photomicrographs, all beautifully clear reproductions, in the "Atlas" at a $\times 10$ magnification which shows the structure of the timbers dealt with. The arrangement of the photomiorographs according to alphabetical order of botanical families, and within each family similarly according to the botanical names of the timber, is exactly parallel with that adopted for the descriptions of the timbers in Bulletin No. 25. An index giving botanical and common names of the timbers is appended.

* Department of Scientific and Industrial Research. Forest Products Research Bulletin No. 26 : An Atlas of End-Grain Photomicrographs 1953.) 12s. $6 d$. net. 